\title{
Comparing Novel Sweet Cherry Crop Load Management Strategies
}

\author{
Matthew D. Whiting ${ }^{1}$ and David Ophardt \\ Washington State University, Irrigated Agriculture Research and Extension \\ Center, 24106 North Bunn Road, Prosser, WA 99350
}

Additional index words. Prunus avium, fruit quality, source-sink relations, blossom thinning, spur extinction, yield, Gisela, rootstock, crop value, biennial bearing

\begin{abstract}
The development of novel crop load management techniques will be critical to the adoption and success of high density sweet cherry orchard systems based on new clonal rootstocks. Herein we report on a comparison of potential means of balancing crop load of 'Bing' sweet cherry grown on the productive and precocious rootstocks 'Gisela 5 ' and 'Gisela 6'. In 2002, thinning treatments were applied to entire trees and consisted of an unthinned control (C), and manual removal of $50 \%$ of the blossoms (B) or $50 \%$ of 2-year-old and older fruiting spurs (S), throughout the tree. In 2003 all trees were left unthinned to characterize the carry-over effect of thinning treatment in 2002. In 2002, compared to $C$, thinned trees had $38 \%$ to $49 \%$ fewer fruit per tree, $22 \%$ to $42 \%$ lower yield, $8 \%$ to $26 \%$ higher fruit weight, and $2 \%$ to $10 \%$ larger fruit diameter. $S$ and $B$ treatments reduced yield by $42 \%$ and $22 \%$ on 'Gisela 5 ' and by $40 \%$ and $31 \%$ on 'Gisela 6', respectively. 'Gisela 5'-rooted trees showed greater improvements in fruit quality than did trees on 'Gisela 6'. Compared to C-, S-, and B-treated trees on 'Gisela 5' yielded fruit that was $15 \%$ and $26 \%$ heavier, respectively. Yield of fruit $\geq 25.5 \mathrm{~mm}$ diameter was increased by $240 \%$ by $\mathrm{S}$ and $880 \%$ by $\mathrm{B}$, though yield of this size fruit was still low (1.5 and 5.2 $\mathrm{kg} /$ tree, respectively). Neither technique had any beneficial carryover effect in the year following treatment despite $S$ trees bearing about $25 \%$ fewer fruit than $B$ and $C$ trees. In both years, 'Gisela 5'-rooted trees bore about $15 \%$ fewer fruit than trees on 'Gisela 6 '. Compared to 'Gisela 5', 'Gisela 6'-rooted trees were about $41 \%, 46 \%$, and $24 \%$ more productive for $C, S$, and $B$, respectively. Number of fruit/tree in 2003 was within $4 \%$ and $8 \%$ of the previous year on 'Gisela 6' and 'Gisela 5', respectively. Crop value analyses suggest growers would be rewarded for producing high yields of medium size fruit (e.g., 21.5 to $25.4 \mathrm{~mm}$ ) compared to low yields of high quality fruit.
\end{abstract}

The commercial adoption of precocious and dwarfing rootstocks in the United States sweet cherry (Prunus avium L.) industry has been limited due to concerns over small fruit size. For example, sweet cherry growers have experienced that the dwarfing rootstock 'Gisela 5' (P. cerasus L. $\times$ P. canescens L.) is overly productive and would not yield high quality fruit. Indeed, Whiting et al. (2005) reported 2- to 6-fold higher yields and reduced fruit quality of 'Bing' sweet cherry grown on 'Gisela 5' and 'Gisela 6' rootstocks, compared to the industry standard, Mazzard (P. avium). However, Whiting and Lang (2004a) showed that high quality 'Bing' sweet cherries can be grown on 'Gisela 5' when fruit number per tree is balanced with the vegetative capacity to supply photoassimilates. Indeed, a negative relationship exists between sweet cherry canopy fruit-to-leaf area ratio (F:LA) and fruit quality (Roper and Loescher, 1987; Whiting and Lang, 2004a), irrespective of rootstock. Earlier reports also have documented poor quality fruit harvested from heavily cropped sweet cherry trees (Proebsting, 1990; Proebst-

Received for publication 17 Dec. 2004. Accepted for publication 3 Mar. 2005. We are grateful to Elizabeth Hansford and Tammy Killian for their technical assistance and to the Washington Tree Fruit Research Commission for financial support of this research.

${ }^{1}$ Author to whom reprint requests should be addressed; e-mail mdwhiting@wsu.edu.
Gisela-rooted trees necessitates the development of novel crop load management strategies to balance fruit number with assimilate supply. For many other tree fruit species, crop load is managed by blossom-and postbloom thinning agents to improve fruit quality and reduce fruit number and total sink demand per tree (Westwood, 1993). Indeed, improvements in apple fruit quality (Guak et al., 2002; Lakso et al, 2001) and value (Marini, 2002; Stover et al., 2001) in response to chemical thinning have been reported. Similar results have been reported for peach (P. persica) (Genard et al., 1999; Miranda-Jimenezand Royo-Diaz, 2002). However, the potential for blossom thinning of sweet cherry has not yet been reported in the literature and no products are currently registered for this purpose.

In apple, research of a centrifugal training concept, requiring the manual removal of spurs, has been employed to optimize light distribution and return bloom, and improve fruit quality (Lauri et al., 1995). Recently, this concept has been modified and tested in productive sweet cherry systems as a crop load management tool (Lauri and Claverie, 2001). In Washington State a similar approach to thinning has been attempted recently on 'Gisela'-rooted trees: in addition to, and during standard dormant pruning, entire spurs are rubbed from limbs with the pruning shears. However, to date there has been no scientific testing of spur thinning in the United States and no reports were found comparing potential sweet cherry crop load management techniques.

The objective of this research was to compare the effects of manual blossom and spur thinning on fruit number, yield, and fruit quality of 'Bing' sweet cherry on the new clonal rootstocks 'Gisela 5' and 'Gisela 6'.

\section{Materials and Methods}

1997; Stopar et al., 2002), though few studies have empirically quantified F:LA. Whiting and Lang (2004a) suggested that conditional fruit growth capacity is limited by the supply of growth resources (i.e., source-limited condition) at less than $200 \mathrm{~cm}^{2}$ leaf area per fruit, within mature 'Bing'/‘Gisela 5' canopies. Based on this, and measured canopy leaf area at tree maturity, they suggested an optimum crop load of about 1800 fruit per tree. This represents about a $50 \%$ reduction in the natural crop load. However, practical strategies for achieving this level of balanced cropping (i.e., fruit number per tree with leaf area) have not yet been evaluated.

In traditional sweet cherry orchard systems based on vigorous seedling rootstocks, sweet cherry crop load is balanced well, albeit inadvertently, by dormant pruning for improved canopy architecture and light distribution. However, this approach is insufficient for trees on productive and precocious 'Gisela' rootstocks and can result in high yields of small fruit (Edin et al., 1996; Whiting and Lang, 2004a). Recent trials found that 'Gisela 5' and 'Gisela 6' rootstocks are less vigorous and significantly more precocious and productive than Mazzard in many locations (Perry et al., 1998) and across several training systems (Whiting et al. 2005). The early and abundant cropping of
Plant material and experimental design. 'Bing' sweet cherry trees, planted in Spring 1995 on 'Gisela 5' and 'Gisela 6' rootstocks and spaced $2.5 \times 5.0 \mathrm{~m}$ in north to south rows, were trained to a free-standing, standard multiple-leader, open-center architecture at Washington State University's Roza research orchard, Prosser, Wash. $\left(46.2^{\circ} \mathrm{N}, 119.7^{\circ} \mathrm{W}\right)$. The soil was a silty loam limited by basalt at a depth of about $1 \mathrm{~m}$. Trees were irrigated with under-tree microsprinklers weekly from mid-April to late October. Standard orchard management practices (irrigation, fertilization, pest control, and dormant pruning) were followed every year. By Spring 2000, trees had just filled their allotted space.

The experimental orchard was about 2.5 ha and comprised of alternating two rows of 'Bing' and one row of 'Rainier' on six different rootstocks that vary in vigor and productivity. In total, 18 experimental 'Bing' trees were selected on the basis of uniform vigor and canopy architecture (within rootstock) and were assigned to a randomized complete block design of six blocks (orchard location) and three single-tree treatments per block. Analyses of variance were conducted using the General Linear Models (GLM) procedure in the Statisti- 
cal Analysis System (SAS) program package (SAS Institute, Cary, N.C.) and means were compared by Fisher's least significant difference (LSD) at 0.05 . Regression analysis was used to determine the relationship between fruit per tree in 2002 and fruit per tree in 2003.

Thinning treatments were imposed at full bloom (13 Apr. 2002) to entire trees and consisted of a control (no manipulation, C), manual removal of $50 \%$ of blossoms (i.e., every second flower, blossom-thinned, B), and manual removal of $50 \%$ of spurs (i.e., every second spur, spur-thinned, S). S trees had only fruiting (i.e., 2-year-old and older) spurs removed, 1-year-old nonfruiting spurs were untouched. To study the subsequent effects of the first year (2002) thinning treatments on return fruiting and fruit quality, no artificial crop load manipulations were imposed in $2003(-\mathrm{C})$. To clarify discussion, the second year (2003) treatments are designated as $\mathrm{C}-\mathrm{C}, \mathrm{B}-\mathrm{C}$, and $\mathrm{S}-\mathrm{C}$, respectively.

Crop value per tree was calculated from fruit yield and size relationships. Values are based upon average returns for fresh market quality 'Bing' sweet cherries from 2002 and 2003 (G. Allan, Allan Bros. Packing, personal communication) and include packaging and marketing fees.

Yield and fruit quality. Fruit number and yield per tree were recorded at harvest (27 June 2002, $74 \mathrm{~d}$ after full bloom [DAFB]; and 25 June 2003, 73 DAFB). From each tree, 100 randomly sampled fruit were evaluated at room temperature for row-size (an industry sales designation related to diameter, see Whiting et al., 2005), mass, firmness (Firmtech, BioWorks Inc., Wamego, Kans.), and soluble solids. Weighted fruit diameter was calculated as the sum of the products of fruit diameter $(\mathrm{mm})$ and the percent of harvested fruit in that diameter category.

\section{Results and Discussion}

In the year of application, thinning reduced fruit number per tree, fruit yield, yield efficiency, and improved fruit quality compared to unthinned control (Fig. 1). Compared to C, for both rootstocks, thinned trees had $38 \%$ to $49 \%$ fewer fruit per tree, $22 \%$ to $42 \%$ lower yield, $8 \%$ to $26 \%$ higher fruit weight, and $2 \%$ to $10 \%$ larger fruit diameter. This general response reflects the negative relationship between fruit-to-leaf area ratio (F:LA) and fruit quality (Roper and Loescher, 1987; Whiting and Lang, 2004a) and more favorable source-sink relations at lower crop loads (i.e., fruit per tree). Similar improvements in fruit quality with reductions in crop load have been documented in many other tree fruit species including apple(Naor et al., 1997; Stopar et al., 2002). However, thinning did not affect fruit soluble solids or firmness in either year (data not shown). This suggests that fruit number did not affect fruit maturity. In contrast, light cropping has advanced significantly apple fruit maturity (Francesconi et al., 1996; Palmer et al., 1997).

Fruit number effects. For both rootstocks, thinning reduced fruit per tree to about half of the unthinned control; on 'Gisela 6', both S and $B$ treatments reduced fruit number by $44 \%$ and on 'Gisela 5', fruit number was reduced by $49 \%$ and $38 \%$ by S and B, respectively (Fig. 1). This observation suggests, at a thinning target of $50 \%$, that fruit set and drop were not affected significantly by thinning, despite altered source-sink relations. Early fruit development likely relies heavily upon stored carbon and nitrogen resources, and therefore is less responsive to current season source-sink relations and competition for assimilates.

Based on the relationship between 'Bing'/ 'Gisela 5' canopy F:LA and fruit quality, Whiting and Lang (2004a) estimated that the ideal number of fruit per mature tree is about 1800. This target was very nearly achieved by each thinning treatment and suggests fruit growth was not limited significantly by assimilate supply; especially on 'Gisela 6', which we hypothesize would have a higher carrying capacity, proportional to its greater canopy volume, assuming a similar relationship. However, tree leaf area (i.e., canopy F: LA ratio) was not determined in this trial. The optimum fruit number per 'Gisela 5'-rooted tree requires about a $50 \%$ reduction of the natural crop load of about 3500 fruit (Fig. 1).

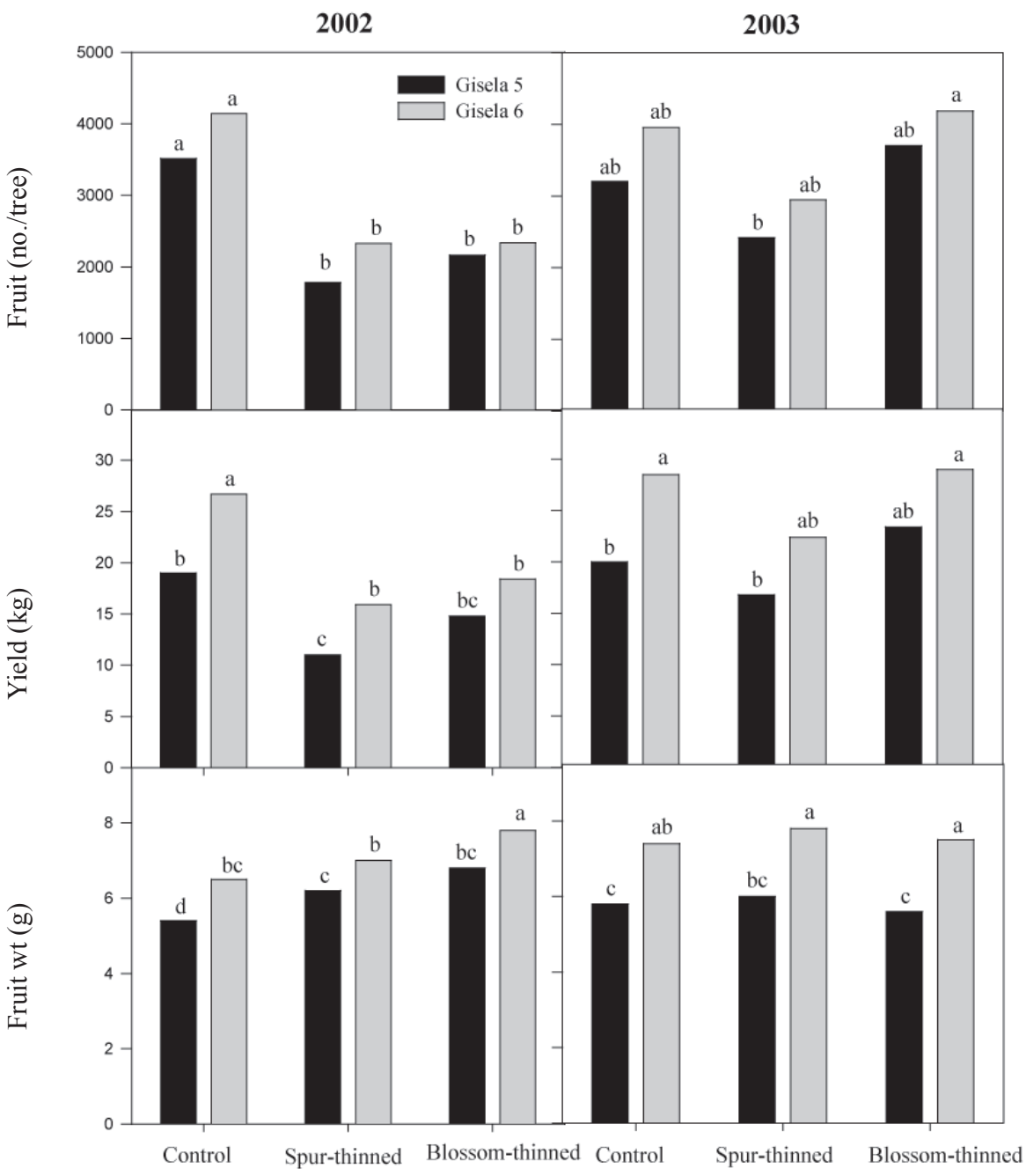

Fig. 1. The effect of thinning treatment on number of fruit per tree, fruit yield $(\mathrm{kg})$, and fruit weight $(\mathrm{g})$ from 8-year-old (2002) and 9-year-old (2003) 'Bing' sweet cherry trees grown on 'Gisela 5' and 'Gisela 6' rootstocks.

This agrees with a previous report (Whiting and Lang, 2004a) and suggests that once the tree is mature, fruit number per tree is rather predictable, barring extreme environmental conditions (e.g., blossom-killing frost). Number of fruit/tree in 2003 was within $4 \%$ and $8 \%$ of the previous year on 'Gisela 6' and 'Gisela 5', respectively. Indeed, comparing fruit number per tree in 2003 to fruit number per tree in 2002 shows no clear relationship (Fig. 2). This result shows that cropping of mature Gisela-rooted sweet cherry trees is regular and does not exhibit an ostensible biennial habit. In contrast, biennial bearing is problematic and related to fruit number in other tree fruit and nut species including apple (Dennis and Neilsen, 1999; Williams and Fallahi, 1999) and pistachio (Pistachia vera L.) (Boler, 1998), for example.

To evaluate the carryover effects of thinning treatments in 2002, all trees were left unthinned in 2003. Compared to 2002, there were $75 \%$ and $31 \%$ more fruit/tree in 2003 for B and S, respectively, and similar quantities for $\mathrm{C}$ (Fig. 1). Moreover, within rootstock, spur-thinned trees had the fewest fruit; on 'Gisela 6' S trees bore $26 \%$ and $30 \%$ fewer fruit than $\mathrm{C}$ and $\mathrm{B}$, respectively; on 'Gisela 5', S trees bore 25\%

2003 
and $35 \%$ fewer fruit than $\mathrm{C}$ and $\mathrm{B}$, respectively. However, these numerical differences were not different statistically $(P=0.23)$. We hypothesize that with greater replication, these differences ( 786 to 1285 fruit/tree) would be significant statistically. Fewer fruit on $\mathrm{S}$ trees is a direct result of spur removal - about $95 \%$ of sweet cherry fruit are borne on 2-year-old and older fruiting spurs (Thompson, 1996). No spur regeneration was noted and we expect these nodes to remain blind. This potential enduring effect of spur thinning might represent an advantage compared to blossom thinning.

In both years, 'Gisela 5'-rooted trees bore about $15 \%$ fewer fruit than trees on 'Gisela 6', likely due to the smaller stature (Perry et al., 1998; Whiting etal., 2005) and, therefore, fewer fruiting sites of 'Gisela 5'-rooted trees.

Fruit yield effects. Fruit yield was reduced significantly in the year of treatment (2002) by $\mathrm{S}$ and $\mathrm{B}$ on 'Gisela 6 ' trees but only by $\mathrm{S}$ on 'Gisela 5'-rooted trees (Fig. 1). Spur- and blossom-thinning treatments reduced yield by $42 \%$ and $22 \%$ on 'Gisela 5 ' and by $40 \%$ and $31 \%$ on 'Gisela 6', respectively. Therefore, for each treatment, the reduction in yield was less, proportionally, than the reduction in number of fruit per tree. An ideal thinning treatment would reduce fruit per tree while not altering yield per tree compared to unthinned. Areduced

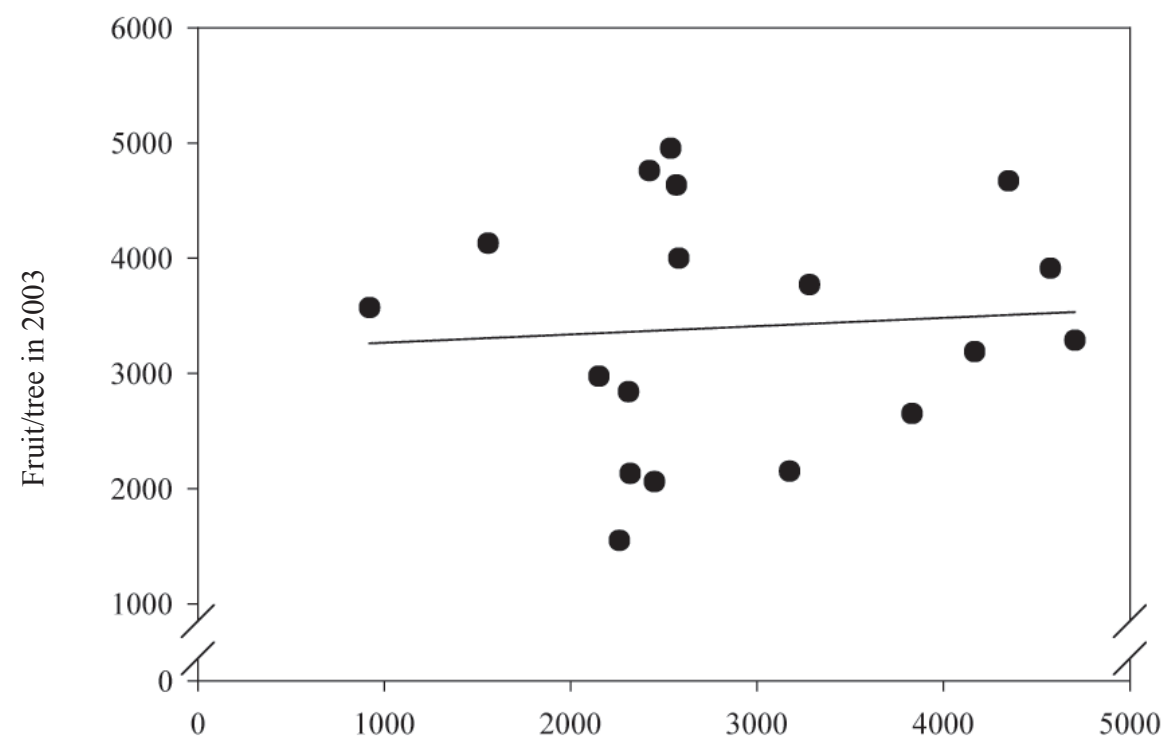

Fruit/tree in 2002

Fig. 2. Relationship between number of fruit per tree in 2002 and 2003 for 8- and 9-year-old 'Bing' sweet cherry trees grown on 'Gisela 5' and 'Gisela 6' rootstocks. Regression equation: y $=3194+0.072 \mathrm{x}$, $r^{2}=0.0054, p \leq 0.77$

Table 1. Effect of thinning treatment (imposed 13 April, 2002) on crop value of 8- and 9-year old 'Bing'/ 'Gisela 5' sweet cherry trees. Trees were unthinned in 2003.

\begin{tabular}{|c|c|c|c|c|c|}
\hline \multirow[b]{3}{*}{ Rootstock } & \multirow{3}{*}{$\begin{array}{c}\text { Thinning } \\
\text { treatment } \\
2002\end{array}$} & \multicolumn{4}{|c|}{ Crop value } \\
\hline & & \multicolumn{2}{|c|}{2002} & \multicolumn{2}{|c|}{2003} \\
\hline & & \$/Tree & $\$ / \mathrm{kg}$ & \$/Tree & $\$ / \mathrm{kg}$ \\
\hline \multirow[t]{3}{*}{ 'Gisela 6' } & Unthinned & 54.3 & 2.03 & 67.8 & 2.38 \\
\hline & Spur & 36.23 & 2.28 & 63.2 & 2.82 \\
\hline & Blossom & 42.81 & 2.33 & 65.9 & 2.27 \\
\hline \multirow[t]{3}{*}{ 'Gisela 5' } & Unthinned & 21.26 & 1.12 & 32.1 & 1.61 \\
\hline & Spur & 20.81 & 1.89 & 30.7 & 1.83 \\
\hline & Blossom & 32.29 & 2.18 & 40.7 & 1.74 \\
\hline
\end{tabular}

has only a slight carryover effect on yield in the subsequent season. This is likely due to a shift in bearing location within trees that were spur-thinned. Asignificant amount of fruit was harvested from 2-year-old spurs, wood which in the previous season was comprised of 1year-old vegetative spurs. These nonfruiting spurs were not thinned in 2002 because they are an important source of photosynthate to basipetal fruit on the 2-year-old fruiting spurs (Roper etal., 1987; Whiting and Lang, 2004b). The recovery of high yields in 2003 suggests a high proportion of fruit was harvested in 2003 from unthinned, 2-year-old spurs though this will vary with pruning severity. Additionally, it is possible that unthinned spurs initiated more floral buds than those from B and $\mathrm{C}$ trees in 2003 , leading to the significant increase in both fruit number and yield/tree in 2003. No data were collected to test this possibility.

Fruit quality effects. Both thinning treatments improved fruit quality in 2002, though the effect varied with rootstock and technique. Overall, B trees showed greater improvements in fruit quality than $\mathrm{S}$ did, and this was particularly true on 'Gisela 5' (Figs. 1 and 3). Compared to the unthinned control, S- and B-treated trees on 'Gisela 5' yielded fruit that was $15 \%$ and $26 \%$ heavier than fruit from $\mathrm{C}$ trees, respectively. Moreover, the yield of premium fruit was increased by $240 \%$ by $\mathrm{S}$ and $880 \%$ by B, though yield of fruit in this category was still low (1.5 and $5.2 \mathrm{~kg} /$ tree, respectively). In addition, both $\mathrm{S}$ and $\mathrm{B}$ treatments reduced significantly the production of the smallest category of fruit, to 1.2 and 0.1 $\mathrm{kg} /$ tree, respectively, whereas about $46 \%$ of fruit from $\mathrm{C}$ trees was in this category (9.2 $\mathrm{kg} /$ tree). Fruit that is $<21 \mathrm{~mm}$ diameter is generally not fresh market quality and is sold through outlets for processing and freezing, for example, at much lower prices.

The improvements in fruit size by $\mathrm{S}$ and B thinning increased estimated crop value per $\mathrm{kg}$ in 2002 by $69 \%$ and $95 \%$, respectively (Table 1), compared to C. However, despite improvements in fruit size and crop value per $\mathrm{kg}$, spur thinning reduced slightly crop value per tree because yield per tree was about $42 \%$ lower than yield from $C$ trees. We hypothesize that, despite slightly lower crop value per tree of $\mathrm{S}$ trees compared to $\mathrm{C}$ trees, production economics would be favorable for $\mathrm{S}$ due to lower costs to harvest fewer fruit per tree. In contrast, B improved crop value per tree by $52 \%$ compared to $\mathrm{C}$. This increase translates to about $\$ 9265 /$ ha at a tree density of $840 /$ ha. This preliminary economic analysis clearly favors B vs. S, reflecting higher prices paid for larger fruit and the greater improvements in fruit size from B compared to S. However, a more detailed economic analysis is needed to fully evaluate potential thinning treatments and develop crop load management recommendations.

On 'Gisela 6', both treatments virtually eliminated the yield of low-value fruit (i.e., $<21 \mathrm{~mm}$ diameter), though unthinned trees yielded very few fruit in this category (Fig. 3). In addition, $\mathrm{S}$ and $\mathrm{B}$ trees yielded about $44 \%$ fewer fruit in the 21.5 to $25.4 \mathrm{~mm}$ category 


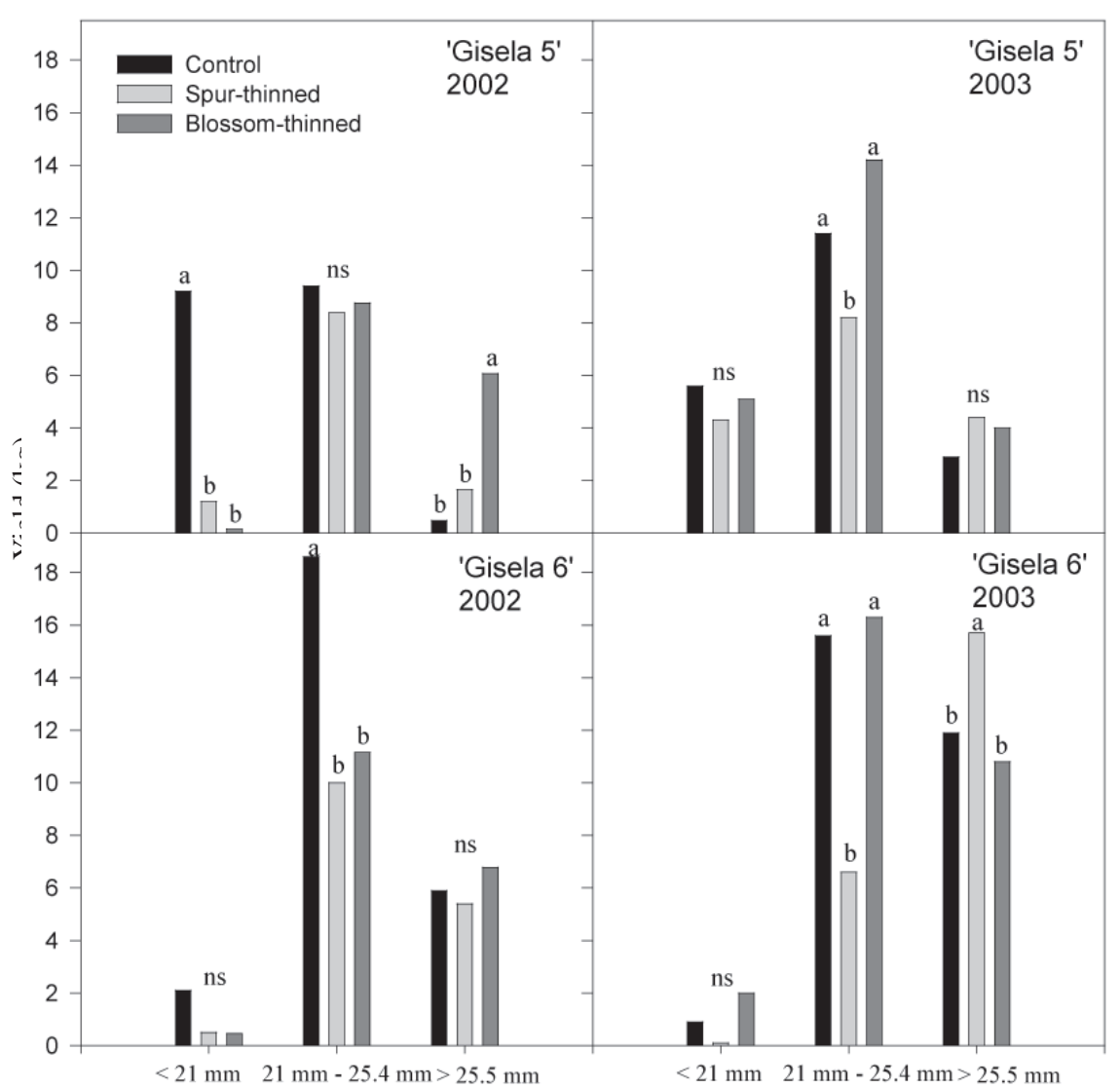

Fig. 3. The effect of spur- and blossom-thinning on fruit yield and size from 8-year-old (2002) and 9-yearold (2003) 'Bing' sweet cherry trees grown on 'Gisela 5' and 'Gisela 6' rootstocks.

without affecting significantly the yield of the largest size fruit. Combined, these effects led to subtle improvements in crop value $/ \mathrm{kg}$ $(+12 \%$ for $\mathrm{S}$ and $+15 \%$ for $\mathrm{B})$, but reductions in crop value/tree of $33 \%$ and $21 \%$ by $S$ and $B$, respectively (Table 1). Only blossom thinning led to statistically significant improvements in fruit weight $(20 \%)$, though improvements in fruit size were subtle and not significant (Figs. 1 and 3). Spur thinning did not improve statistically fruit weight or yield of the largest fruit (i.e., $>25.5 \mathrm{~mm}$ diameter) compared to $\mathrm{C}$, despite a $40 \%$ to $44 \%$ reduction in yield and fruit number. Therefore, the fruit size and crop value response to thinning 'Gisela 6'-rooted trees was different to that of trees on 'Gisela 5 '. This result highlights the need to comprehend rootstock-induced effects on tree productivity, source-sink relations, and carrying capacity when designing thinning strategies. Moreover, the greater and consistent improvements in crop value from $B$, and the inconsistent effect of $\mathrm{S}$ across rootstocks, suggest that blossom thinning is a better crop load management technique than spur thinning.

We hypothesize that the greater improvements in fruit size from B vs. S are due treatment effects on canopy and, especially, spur F:LA, though these parameters were not measured explicitly. Manually thinning blossoms improves fruit quality by balancing $\mathrm{F}$ : LA at the individual spur level; fruit sinks are removed while spur leaf area is unaffected. In contrast, $\mathrm{S}$ trees had entire heavily cropped spurs removed, thereby improving F:LA on a scaffold or canopy basis, but leaving F:LA of individual spurs unchanged compared to $\mathrm{C}$. Our data suggest that spur source-sink relations are most important in determining fruit quality because spur leaves are the key suppliers of photosynthate for fruit growth and development (Roper et al., 1987). Moreover, S and C trees may have had less leaf area per spur to support fruit growth and development because leaf area per spur is related negatively to $F$ : LA (Whiting and Lang, 2004a). Therefore, to maximize fruit quality, fruit thinning strategies should balance fruit number per spur rather than fruit number per limb or tree.

There were no effects of 2002 thinning treatment on fruit weight in 2003 (Fig. 1). However, for 'Gisela 6'-rooted trees, we documented a $32 \%$ increase in the yield of premium quality fruit (i.e., $>25.5 \mathrm{~mm}$ ) and a $58 \%$ decrease in the yield of 21.5 to $25.4 \mathrm{~mm}$ fruit from S-C compared to B-C and C-C (Fig. 3). The increase in the yield of largest fruit meant that in 2003 , $\mathrm{S}-\mathrm{C}$ trees exhibited the highest crop value, on a per kg basis (Table 1). However, due higher yields of 21.5 to $25.4 \mathrm{~mm}$ fruit, smaller fruit still valuable on the fresh market, both B-C and $\mathrm{C}-\mathrm{C}$ trees yielded crops of higher value than $\mathrm{S}-\mathrm{C}$, on a per tree basis. Interestingly, in 2003, S-C trees on 'Gisela 5' exhibited a similar decrease in 21.5 to $25.4 \mathrm{~mm}$ fruit to 'Gisela 6 '-rooted trees, but did not show an increase in premium size fruit or decline in the smallest fruit category. As a consequence, S-C trees in 2003 had lower crop value/tree compared to the other treatments (Table 1).

Our analyses show that producing high quality fruit may not be the best economic strategy, given the current pricing structure for sweet cherries. Growers would be rewarded for producing high yields of medium size fruit (e.g., 21.5 to $25.4 \mathrm{~mm}$ ) compared to low yields of high quality fruit (Table 1). This agrees with a previous analysis of apple crop load vs. crop value (Stover et al., 2001). Optimum fruit number should be based upon the interactions among yield, fruit quality, and pricing per size category; the relationships among which will vary yearly, depending upon several factors not under a grower's control.

Fruit from 'Gisela 6'-rooted trees were higher quality than fruit from trees on the more dwarfing 'Gisela 5'. In 2002, fruit weight from 'Gisela 6'-rooted trees was about 20\%, 13\%, and $15 \%$ higher than that from trees on 'Gisela 5 ' for C, S, and B, respectively (Fig. 1). Again, in 2003, fruit from 'Gisela 6'-rooted trees were about $28 \%$ - 33\% heavier than fruit from trees on 'Gisela 5'. This is likely due to improved canopy source-sink relations on 'Gisela 6' compared to 'Gisela 5' because trees on 'Gisela 6' had similar numbers of fruit (Fig. 1) on larger canopies. We did not determine canopy leaf area in this trial but Whiting et al. (2005) reported about $50 \%$ greater trunk cross-sectional area (TCSA) of 9-year-old 'Bing' trees on 'Gisela 6 'vs. 'Gisela 5' and TCSA is related positively to leaf area (Suzuki, 2003). Therefore, our current data suggest a lower fruiting density on 'Gisela 6' (i.e., similar number of fruit on larger canopy). Moreover, in recent studies, we have recorded no difference in 'Bing' leaf size or net $\mathrm{CO}_{2}$ exchange rate when grown on 'Gisela 6' or 'Gisela 5' (Whiting, unpublished). Therefore, compared to trees on 'Gisela 5', spur source-sink relations are favorable on 'Gisela 6 '. Fruit to leaf area ratio is the most important within-tree factor affecting fruit quality (Patten etal., 1986; Roper and Loescher, 1987; Whiting and Lang, 2004a).

It is also possible that 'Gisela 6' altered dry matter partitioning in favor of fruit over other competing sinks, compared to 'Gisela 5 '. Rootstock affects dry matter partitioning in other species, including peach (Inglese et al., 2002) and apple (Stutte et al., 1994). Additionally, canopy net $\mathrm{CO}_{2}$ exchange, and therefore assimilate supplies, of 'Gisela 5'-rooted trees may have been limited by an unnaturally poor light environment in the experimental orchard, compared to a commercial scenario where all trees would be on the same rootstock (i.e., similar height). Shading from neighbouring, more vigorous trees such as those grown on Mazzard and 'Gisela 6' may have played a role, especially in the early-mid morning and late afternoon (i.e., at low zenith angles). 'Gisela 6 '-rooted trees would not have been subject to such shading because they are among the most vigorous trees in the experimental orchard.

From an examination of fruit number, tree yield, and fruit quality in the year of thinning and the subsequent season, it is apparent that these thinning strategies will require an annual application. Neither technique had any beneficial carryover effect in the year following treatment despite spur-thinned trees bearing about $25 \%$ fewer fruit than $\mathrm{B}$ and $\mathrm{C}$ trees. This suggests that one potential advantage of spur 
thinning, the need to thin only once every 2 to 3 years, is not relevant. Again, this is likely due to the high F:LA of the remaining spurs.

\section{Conclusions}

Novel crop load management strategies must be developed for sweet cherry production systems based on new clonal, precocious, productive, and sometimes dwarfing rootstocks such as those in the Gisela series. Current strategies based on dormant pruning are insufficient. Herein we tested two model systems which varied in their effect upon yield and fruit quality in the year of treatment and subsequent season. In addition, the thinning response was not consistent across rootstock. The potential and necessity to improve sweet cherry fruit quality and crop value per tree is greater within orchard systems that exhibit inherently high canopy per spur F:LA, such as 'Bing'/“Gisela 5'. 'Bing'/“Gisela 6' trees possessed lower fruiting density and therefore responded less favorably to thinning.

The eventual commercial application of any crop load management strategy will depend upon many factors not evaluated herein. These may include cost, reliability, and ease of treatment. Further analyses, especially economic, appear warranted and should include a treatment of modified dormant pruning (i.e., designed specifically to manage crop load) and chemical thinning. Clearly, the manual removal of blossoms is not a practical approach to thinning for sweet cherry growers. Possible chemical thinning strategies for sweet cherry are under investigation (Whiting, unpublished), though no products are currently registered for this purpose. The effect of a chemical thinning program on sweet cherry fruit yield and quality may not match that from our manual blossom removal due to potential reduction in net $\mathrm{CO}_{2}$ exchange rate (Untiedt and Blanke, 2001) from thinners.

\section{Literature Cited}

Boler, K. 1998. Effects of bud thinning and pruning on alternate bearing and nut quality of pistachio (Pistacia vera L.). Acta Hort. 470: 507-509.

Dennis, F.G. and J.C. Neilsen. 1999. Physiological factors affecting biennial bearing in tree fruit: the role of seeds in apples. HortTechnology 9:317-322.

Edin, M., A. Garcin, J. Lichou, and J.M. Jourdain.
1996. Influence of dwarfing cherry rootstocks on fruit production. Acta Hort. 410:239-245.

Francesconi, A.H.D., C.B. Watkins, A.N. Lakso, J.P. Nyrop, J. Barnard, and S.S. Denning. 1996. Interactions of European red mite and crop load on maturity and quality, mineral concentrations, and economic value of 'Starkrimson Delicious' apples. J. Amer. Soc. Hort. Sci. 121:967-972.

Genard, M., F. Lescourret, and M. Ben-Mimoun. 1999. Simulation of the effect of fruit thinning on peach quality. Acta Hort. 499:61-68.

Guak, S., M. Beulah, N.E. Looney, and L.H. Fuchigami. 2002. Thinning 'Fuji' apple blossoms with synthetic auxins (MCPB-ethyl or NAA) and ethephon with or without postbloom thinning with carbaryl. J. Amer. Soc. Hort. Sci. 127:165-170.

Inglese, P., T. Caruso, G. Gugliuzza, and L.S. Pace. 2002. Crop load and rootstock influence on dry matter partitioning in trees of early and late ripening peach cultivars. J. Amer. Soc. Hort. Sci. 127:825-830.

Lakso, A.N., T.L. Robinson, M.C. Goffinet, and M.D. White. 2001. Apple fruit growth responses to varying thinning methods and timing. Acta Hort. 557:407-412.

Lauri, P.E., E. Térouanne, J.M. Lespinasse, J.L. Regnard, and J.J. Kelner. 1995. Genotypic differences in the axillary bud growth and fruiting pattern of apple fruiting branches over several years - An approach to regulation of fruit bearing. Sci. Hort. 64:265-281.

Lauri, P.E. and J. Claverie. 2001. Principes et practiques de 1'extinction. Reussir Fruits Legumes 199:42-45.

Marini, R.P. 2002. Thinning 'Golden Delicious' and spur 'Delicious' with combinations of carbamates and NAA. HortScience 37:534-538.

Miranda-Jimenez, C. and J.B. Royo-Diaz. 2002. Fruit distribution and early thinning intensity influence fruit quality and productivity of peach and nectarine trees. J. Amer. Soc. Hort. Sci. 127:892-900.

Naor, A., I. Klein, I. Doron, Y. Gal, Z. Ben-David, and B. Bravdo. 1997. Irrigation and crop load interactions in relation to apple yield and fruit size distribution. J. Amer. Soc. Hort. Sci. 122:411-414

Palmer, J.P., R. Giuliani, and H.M. Adams. 1997. Effect of crop load on fruiting and leaf photosynthesis of 'Braeburn'/M.26 apple trees. Tree Physiol. 17:741-746.

Patten, K.D., M.E. Patterson, and E.L. Proebsting. 1986. Factors accounting for the within-tree variation of fruit quality in sweet cherries. J. Amer. Soc. Hort. Sci. 111:356-360.

Perry, R.L., G. Lang, R. Andersen, L. Anderson, A. Azarenko, T. Facteau, D. Ferree, A. Gaus, F. Kappel, F. Morrison, C. Rom, T. Roper, S. Southwick, G. Tehrani, and C. Walsh. 1998. Performance of the NC-140 cherry rootstock trials in North America. Acta Hort. 468:291-296.

Proebsting, E.L. 1990. The interaction between fruit size and yield in sweet cherry. Fruit Var. J. 44:169-172.

Proebsting, E.L. and H.H. Mills. 1981. Effects of season and crop load on maturity characteristics of 'Bing' sweet cherry. J. Amer. Soc. Hort. Sci. 106:144-146.

Roper, T.R. and W.H. Loescher. 1987. Relationships between leaf area per fruit and fruit quality in 'Bing' sweet cherry. HortScience 22:1273-1276.

Roper, T.R., W.H. Loescher, J. Keller, and C.R. Rom. 1987. Sources of photosynthate for fruit growth in 'Bing' sweet cherry. J. Amer. Soc. Hort. Sci. 112:808-812.

Stopar, M., U. Bolcina, A. Vanzo, and U. Vrhovsek. 2002. Lower crop load for cv. Jonagold apples (Malus $\times$ domestica Borkh.) increases polyphenol content and fruit quality. J. Agr. Food Chem. 50:1643-1646.

Stover, E., F. Wirth, and T. Robinson. 2001. A method for assessing the relationship between cropload and crop value following fruit thinning. HortScience 36:157-161.

Stutte, G.W., T.A. Baugher, S.P. Walter, D.W. Leach, D.M. Glenn, and T.J. Tworkski. 1994. Rootstock and training system affect dry-matter and carbohydrate distribution in 'Golden Delicious' apple trees. J. Amer. Soc. Hort. Sci. 119:492-497.

Suzuki, M. 2003. Size structure of current-year shoots in mature crowns. Ann. Bot. 92:339-347.

Thompson, M. 1996. Flowering, pollination and fruit set, p. 223-241. In: A.D. Webster and N.E. Looney (eds.). Cherries: Crop physiology, production and uses. CAB Intl., Wallingford, U.K

Untiedt, R. and M. Blanke. 2001. Effects of fruit thinning agents on apple tree canopy photosynthesis and dark respiration. Plant Growth Regulat. 35:1-9.

Westwood, M.N. 1993. Fruit growth and thinning, P. 254-274. In: Temperate zone pomology. Timber Press, Portland, Ore.

Whiting, M.D. and G.A. Lang. 2004a. 'Bing' sweet cherry on the dwarfing rootstock 'Gisela 5': Thinning affects tree growth and fruit yield and quality but not net $\mathrm{CO}_{2}$ exchange. J. Amer. Soc. Hort. Sci. 129:407-415

Whiting, M.D. and G.A. Lang. 2004b. Effects of leaf area removal on sweet cherry vegetative growth and fruit quality. Acta Hort. 636: 467-472.

Whiting, M.D., G.A. Lang, and D. Ophardt. 2005. Rootstock and training system affect sweet cherry growth, yield, and fruit quality. HortScience (in press).

Williams, K.M. and E. Fallahi. 1999. The effects of exogenous bioregulators and environment on regular cropping of apple. HortTechnology 9:323-327. 